\title{
Experimental Study of Thermal Performance in a Closed Loop Pulsating Heat Pipe with Alternating Superhydrophobic Channels
}

\author{
Luis Betancur $^{1 *}$, Daniele Mangini ${ }^{2}$, Marcia Mantelli ${ }^{1}$ and Marco Marengo ${ }^{3}$ \\ ${ }^{1}$ Department of Mechanical Engineering, Federal University of Santa Catarina, Florianopolis 88040-900, Brazil \\ ${ }^{2} H E$ Space for ESA, Directorate of Human and Robotic Exploration Programmes (HRE-RS), European Space Agency, AG \\ Noordwijk, The Netherlands \\ ${ }^{3}$ School of Computing, Engineering and Mathematics, University of Brighton, Brighton, United Kingdom
}

\begin{abstract}
A Pulsating Heat Pipe (PHP) with alternating hydrophilic/superhydrophobic channels was tested at vertical position, bottom heat mode and different heat power inputs. The device consists in a copper tube (internal/external diameters of 3.18/4.76 mm), bent into a planar serpentine of ten channels and five U-turns. The tube is partially functionalized with a superhydrophobic coating, in such a way to create an alternation of hydrophilic and superhydrophobic surfaces on the straight tubes along the loop, in the condenser zone. The aim is to investigate how the alternated wettability affects the startup, the fluid motion along the tubes and the overall thermal performance of the device, which is compared to another PHP, having the same geometry and under the same working conditions, but completely hydrophilic. Distilled water, at 50\% filling ratio is the working fluid. Power inputs varying from 20 to up to $350 \mathrm{~W}$, in a stepwise increasing and decreasing fashion, are applied to the PHP. The condenser temperature is kept constant, at $20^{\circ} \mathrm{C}$. The device is monitored by sixteen thermocouples and one pressure transducer, mounted in contact to the fluid in the condenser region. Data analysis shows that the alternating wettability of tube sections strongly affects the flow motion, the start-up and the overall performance. In general, the alternating PHP presents a worse overall thermal performance: the thermal resistance is always higher and the start-up is achieved at higher heating power levels. Temperature at superhydrophobic surfaces exhibit a flat trend, suggesting that the flow was blocked in the functionalized area surface, while, for the hydrophilic inserts, more pronounced temperature fluctuations are observed. It is believed that the superhydrophobic coating hinders the liquid film formation, decreasing locally the flow motion. On the other hand, the enhancement of the inner wettability improves the flow motion, as the liquid film that covers the inner surface acts as lubricant.
\end{abstract}

Keywords: Closed Loop Pulsating Heat Pipes; Alternating Channels; Wettability; superhydrophobic Coating

\section{NOMENCLATURE}

Q : Thermal power (W)

$\Delta \mathrm{T} \quad$ : Difference of temperature $\left({ }^{\circ} \mathrm{C}\right)$

$\mathrm{R}_{\mathrm{t}} \quad$ : Equivalent resistance $\left({ }^{\circ} \mathrm{C} / \mathrm{W}\right)$

$\theta_{\mathrm{A}} \quad:$ Advancing contact angle $\left({ }^{\circ}\right)$

$\theta_{\mathrm{r}} \quad$ : Receding contact angle $\left({ }^{\circ}\right)$

$\Delta \theta \quad$ : Hysteresis contact angle $\left(^{\circ}\right)$

$\bar{T}_{e} \quad$ : Mean temperature at evaporator zone $\left({ }^{\circ} \mathrm{C}\right)$

$\bar{T}_{c} \quad$ : Mean temperature at condenser zone $\left({ }^{\circ} \mathrm{C}\right)$

\section{INTRODUCTION}

The use of high performance electronic components has increased the amount of heat to dissipate during their operation. The maximum temperature of electronics must be kept bellow a critical threshold value; otherwise, both the performance and the lifespan will decrease abruptly. Therefore, higher performance heat exchange systems for higher heat fluxes must be explored. Currently, some applications produce fluxes that can vary from 10 to $40 \mathrm{~W} / \mathrm{cm}^{2}$ [1]. In most applications, such as terrestrial and space, reliable, low-weight, high heat transfer capacity devices are required. Several different types of heat transfer devices such as conventional heat pipes, loop heat pipes and capillary pumped loops [2] can be applied. However, the major problems regarding these solutions are related to the complexity of their manufacturing processes. In this context, the pulsating heat pipes (PHP), a relatively new two-phase passive heat exchanger proposed in the early 1990s by Akachi (1990) [3], with very promising advantages such as flexibility, low costs, reproducibility and, above all, the possibility to extract efficiently high heat fluxes, can meet all these requirements. The use of PHP for electronics thermal 
control is promising for high power level and high heat flux density cases [4][5][6].

PHPs are highly efficient heat exchanger devices. It basically consists of an evacuated small diameter closed tube, bent in multiple turns, where a certain amount of working fluid is inserted. PHPs are composed of two main regions: evaporator, where heat is inserted, and condenser, where heat is removed. An adiabatic section, consisting of a thermally insulated region located between the evaporator and the condenser, may have a variable dimension or even not exist. PHPs operate in closed two-phase chaotic cycles. Confined saturated liquid, when heated, forms slugs of liquid and plugs of vapor. Due to the confinement, PHPs use latent heat of vaporization to generate vapor, expanding the bubbles and pushing the liquid slugs to the condenser region. The high-speed cycles are responsible for the efficiency of the working fluid latent and sensible heat transportation.

Considering the PHP family, the closed loop pulsating heat pipes (CLPHP) have better thermal performance than the open loop pulsating heat pipes (OLPHP), as they provide the possibility of fluid circulation. Numerous techniques were studied to enhance the flow circulation in a preferential direction within CLPHPs. In order to improve the thermal performance of CLPHP, some researchers studied the influence of increasing the number of turns and of introducing valves in the circuit [7]. Although efficient, check valves increase the manufacturing complexity of the devices, as highlighted by [8]. However, there can be geometry limitations for the number of turns in actual applications. Other works point out that hydraulic asymmetries could enhance the flow circulation and, thus, the overall performance of the device. Recent works as [8] are focused on the visualization of the PHP hydrodynamic behavior and on the heat transfer measurements of a CLPHP with variable cross section area channels. They noticed that CLPHP with uniform channels are more sensitive to inclination. Moreover, CLPHPs with non-uniform cross section areas worked in all inclinations tested.

On the other side, different researchers showed that the surface wettability influences the vapor and liquid slug motion and so, the thermal performance of PHP [9] [10] [11]. Actually, the presence of thin films over internal surfaces, surrounding the vapor plugs, is related to the surface wettability. These films usually improve the heat transfer capacity when applied to the evaporator sections of the device [10][12]. Works as [9] and [10] show that the heat transfer capacity of PHPs can be improved with different wettability patterns along the channels. Also, the literature reports a performance improvement in phase change heat exchangers by using a hydrophobic surface in condensers, so that condensation happens in dropwise mode [13], and by improving the wettability in evaporators, to avoid dry patches [14] and to create a liquid film around the vapor plug [9] [15]. The idea behind the concept of using different cross section area channels is to create unbalancing capillary pressures by receding and advancing contact angle hysteresis [16] [17]. The literature shows improvements of PHPs based on wettability modification and capillary unbalancing, having into account the importance of dynamic contact angle in two phase flow in capillary tubes [18], however, it was never tested the effect of alternating channels with hydrophilic and superhydrophobic coatings to create capillary unbalancing. The present work is focused on the study of the start-ups of a closed loop PHP with alternating hydrophilic and superhydrophobic channels under different experimental conditions, which are compared to those of a bare PHP, reported by Betancur et al., in 2017 [19]. The superhydrophobic surfaces are obtained by functionalizing the internal bare copper tube by chemical coating. The main contribution of the present work to the state of the art in PHPs consists of the study of a PHP which the wettability of the surfaces are unbalanced, i.e., for a unique $U$ turn branch, one side is superhydrophobic and the other hydrophilic. With this study, the importance of the surface property "wettability", and thus of the liquid film formation, on the thermal performance of PHP is addressed.

\section{EXPERIMENTAL SET UP}

In order to quantify how much coatings affect the wettability of surfaces, a copper surface sample is functionalized, spreading Glaco ${ }^{\circledR}$ superhydrophobic coating to form a thin layer. The advancing $\left(\theta_{\mathrm{A}}\right)$, receding $\left(\theta_{\mathrm{r}}\right)$ and the hysteresis contact angles $(\Delta \theta)$ of a water-air mixture are measured in a superhydrophobic surface and in a not-functionalized one (hydrophilic) [20]. The measurements are repeated in five different points of each surface. Results, in terms of averaged measurement and standard deviation, are shown in Table 1.

Table 1. Wetting properties of Superhydrophobic and Hydrophilic copper surfaces.

\begin{tabular}{cccc}
\hline Surface & $\theta_{\mathrm{A}}$ & $\theta_{\mathrm{r}}$ & $\Delta \theta$ \\
\hline Hydrophilic & $89^{\circ} \pm 3.6^{\circ}$ & $45.5^{\circ} \pm 5.1^{\circ}$ & $45.2^{\circ} \pm 6.2^{\circ}$ \\
Superhydrophobic & $164.5^{\circ} \pm 2.1^{\circ}$ & $159.3^{\circ} \pm 5.1^{\circ}$ & $5.2^{\circ} \pm 5.5^{\circ}$ \\
\hline
\end{tabular}

The alternating functionalized PHP studied consists of a copper capillary tube with $4.76 \mathrm{~mm}$ of outer diameter (OD) and $3.18 \mathrm{~mm}$ of inner diameter (ID), bent in a planar geometry, resulting in five U-turns at the evaporator. 
The internal surfaces of half of the longitudinal tubes are alternately functionalized with Glaco ${ }^{\circledR}$ coating, creating an alternation of superhydrophilic and superhydrophobic surfaces, on the straight tubes along the loop, in the condenser zone, as shown in Fig. 1. To allow for the access to the internal PHP surfaces to functionalize selected regions, the serpentine is cut in several pieces, as shown in Fig. 2. The surface treatment is performed following the procedure: 1) the volume of the region to be functionalized is determined, in the present case, this volume is of $1 \mathrm{ml}$;2) the tube piece to be treated is connected, in one end and by a silicon hose, to a pipette containing a minimum of $10 \mathrm{ml}$ of distillated water, while a recipient containing Glaco ${ }^{\circledR}$ is connected to the other end (see Fig 2.a), where water and Glaco are separated by air; 3) the pipette piston was scrolled up to dislocate the air and the liquid column in $1 \mathrm{ml}$, as showed in Fig. $2 \mathrm{~b}$ : as the water column is displaced, Glaco ${ }^{\circledR}$ is sucked into the channel to be functionalized; 4) the piston was scrolled down until it returned to its initial position removing most of the Glaco $^{\circledR}$ that was inside the functionalized channel (Fig. 2c), remaining only a thin layer over the internal surface; 5) the tube was disconnected from both water and Glaco ${ }^{\circledR}$ reservoir and placed in vertical position for at least 15 minutes until the superhydrophobic coating dried. This process was repeated for the five functionalized channels.

All the hydrophilic and superhydrophobic inserts are connected using a low-outgassing glue (Torr Seal $\left.{ }^{\circledR}\right)$, in such a way to alternate the hydrophilic and superhydrophobic sections (Fig. 1), building the functionalized closed loop PHP. When the glue dries, the device is vacuumed down in a Vacuum pump (Edwards RV8 ${ }^{\circledR}$ ) up to $1 \times 10^{-6}$ [mbar]. An Edwards Spectron 5000 Leak Detector ${ }^{\circledR}$ equipment is used to check the device sealing. Finally, the PHP is charged with distilled water in a volume ratio of $50 \%$ [8.2 $\pm 0.1 \mathrm{ml}]$. The water was first degassed by continuous vacuuming cycles, utilizing a volumetric pump. The internal pressure is monitored by a high accuracy pressure transducer (Keller M5-HB ${ }^{\circledR}$ ) located at the condenser zone.

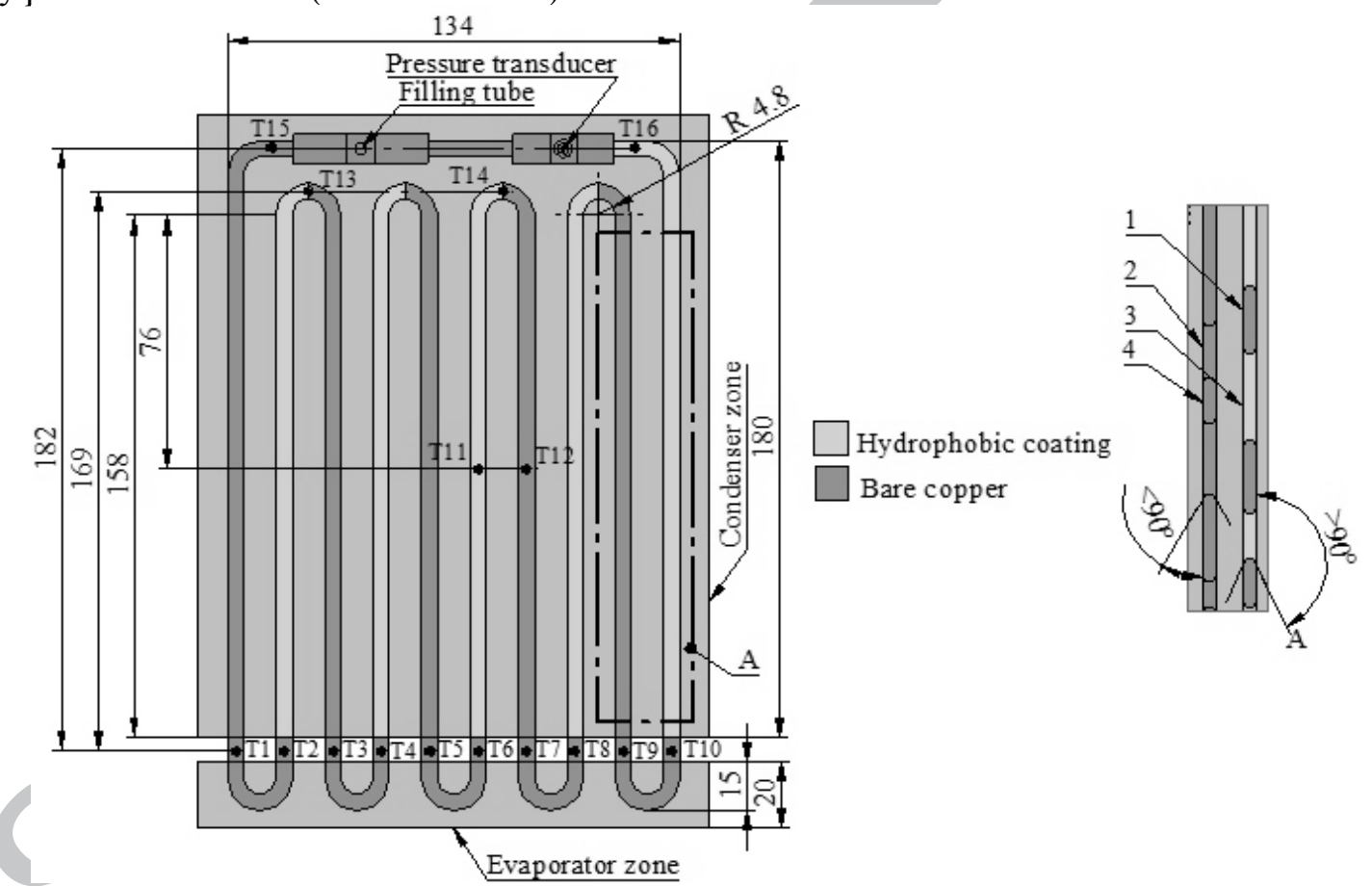

Fig. 1. PHP with superhydrophobic alternating channels. Detail A depicts advancing angle $\theta_{\mathrm{A}}$ and receding angle $\theta_{\mathrm{r}}$. $\theta_{\mathrm{A}}$ and $\theta_{\mathrm{r}}<90^{\circ}$ for hydrophilic copper channel and $>90^{\circ}$ for superhydrophobic channels. In detail A, item 1 and 2 depicts a liquid slug; by other side, item 3 and 4 depicts a vapor plug.

The temperature distribution of the functionalized PHP is monitored by sixteen T-type thermocouples $\left( \pm 0.9^{\circ} \mathrm{C}\right.$ of maximum uncertainty) as shown in Fig. 1. A DAQ-NI SCXI-1000® data acquisition system is used to record data during the experiment. The PHP is assembled in a cold plate formed by two aluminum blocks as shown in Fig. 3. The cold plate is connected to a thermal bath (Lauda ${ }^{\circledR}$ Proline RP855), able to control the bath temperature with $\pm 0.1^{\circ} \mathrm{C}$ of temperature variation. In order to assure the contact, circular cross section channels are milled on both heat sink plates. The thermal contact between the functionalized PHP and the cold plate is improved by spreading a thin layer of Omegatherm ${ }^{\circledR} 201$ thermal grease over the heat exchanging contact surfaces. 


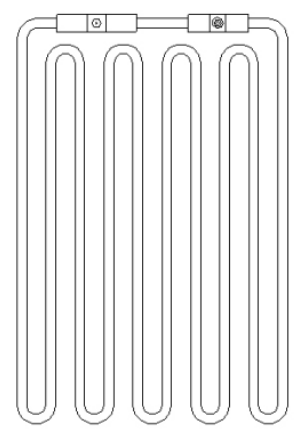

Meandered tube

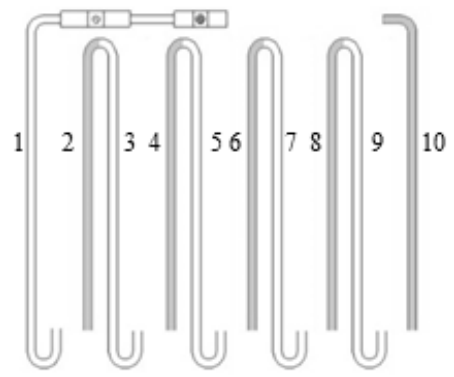

Serpentine cuts and selected tubes to be functionalized

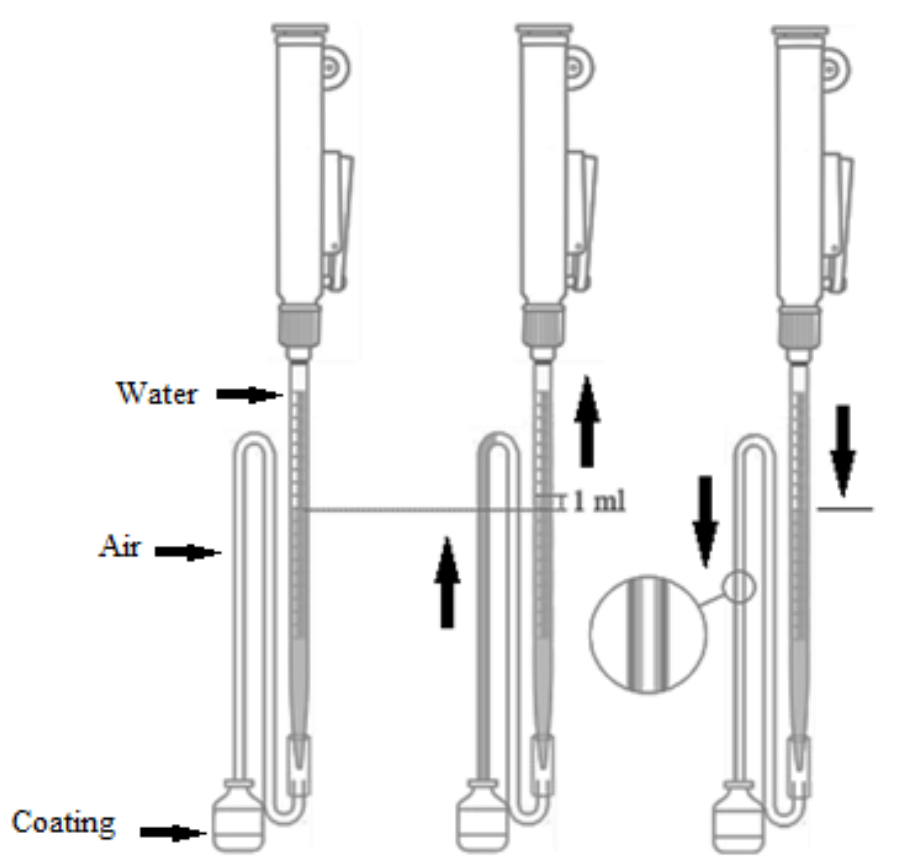

a.

b.

c.

Functionalization process

Fig. 2. Functionalization steps. Left: serpentine was divided in six parts, where section 2, 4, 6, 8 and 10 are functionalized. a) The coating reservoir is located left side and water reservoir at right. Tube initially contains air. b) The water is displaced when pipette piston is scrolled up and the coating is sucked into the tube, air avoids Glaco and water contact. c) The piston is scrolled down, water returns at initial position and coating leaves the tube, remaining only a thin coating layer, as shown in zoom of step c.

Heat is provided to the evaporator by two cartridge heaters (HLP ${ }^{\circledR}$ type, OD $10 \mathrm{~mm}$ and $100 \mathrm{~mm}$ length) embedded in the copper block, which are thermally insulated by mineral wool. Heaters are connected to a power supply (TDK-Lambda GEN300-17 ${ }^{\circledR}$ ) that can provide an electric power input of up to 5,000W. The evaporator region comprises the area in contact with the heaters while the condenser occupies the remaining area.

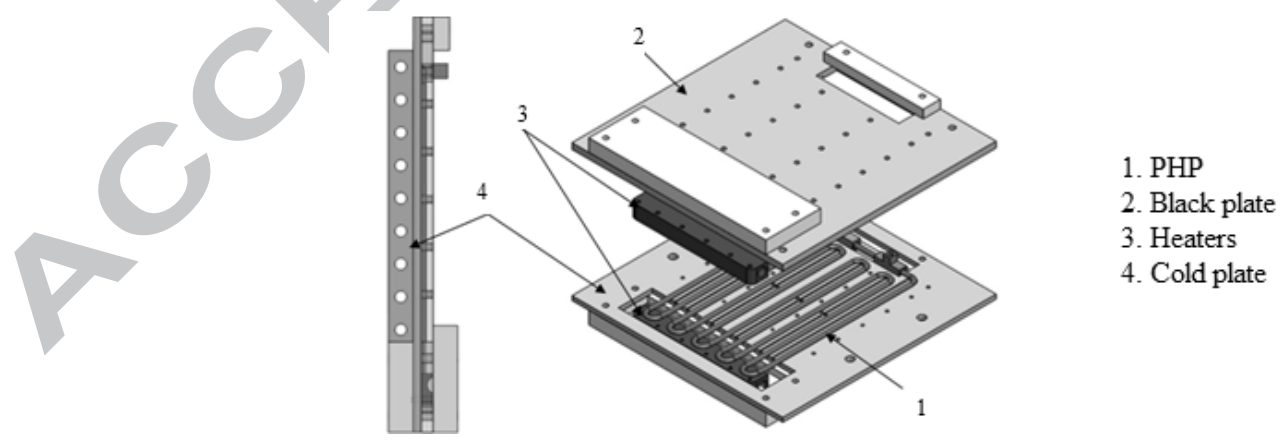

Fig. 3. Experimental block. 1) PHP instrumented with 16 Type T thermocouples and miniature pressure transducer at condenser zone. 2) Back plate to fix the PHP to the cold plate. 3) Heaters cartridge type, electrical power supplied by TDK lambda GEN300-17. 4) Cold plate containing 9 holes that allows the water inlet, at controlled temperature, supplied by Lauda Proline RP855 thermal bath.

The following test methodology was applied. The condenser temperature is set at $20^{\circ} \mathrm{C}$ by the thermal bath control system. Time is given until all the temperatures, both at the evaporator and at the condenser zones, stabilize. Experiments are carried out at vertical position in the bottom heat mode, with the power increased and then decreased by $20 \mathrm{~W}$ steps, as follows: 20, 40, 60, 80, 100, 140, 180, 230, 290, 350, 290, 
$230,180,140,100,80,60,40,30$ and 20 [W]. Each power level is maintained for 900 seconds to guarantee the pseudo stable regime, considered achieved when the variation of $\mathrm{T}_{\text {evap }}$ was less than $0.5^{\circ} \mathrm{C} / \mathrm{min}$. The experimental procedure is based on the one used by Betancur et al., (2017) [19] to allow for the comparison between results and so to enable the analyzes of the effect of alternating pattern of wettability in a PHP.

\section{RESULTS AND DISCUSSION}

Experimental results of functionalized PHP were obtained for the same experimental parameter configurations presented by [19] for a conventional PHP. Figure 4 shows temperature measurements for thermocouples 11,12 and 14 , located at the superhydrophobic coating tube, bare copper tube and at the transition point between both tube regions, i.e., following a single turn inside the condenser, as shown in Fig. 1. For the studied functionalized PHP, thermocouples measurement allows to analyze the difference between bare and alternating channels.

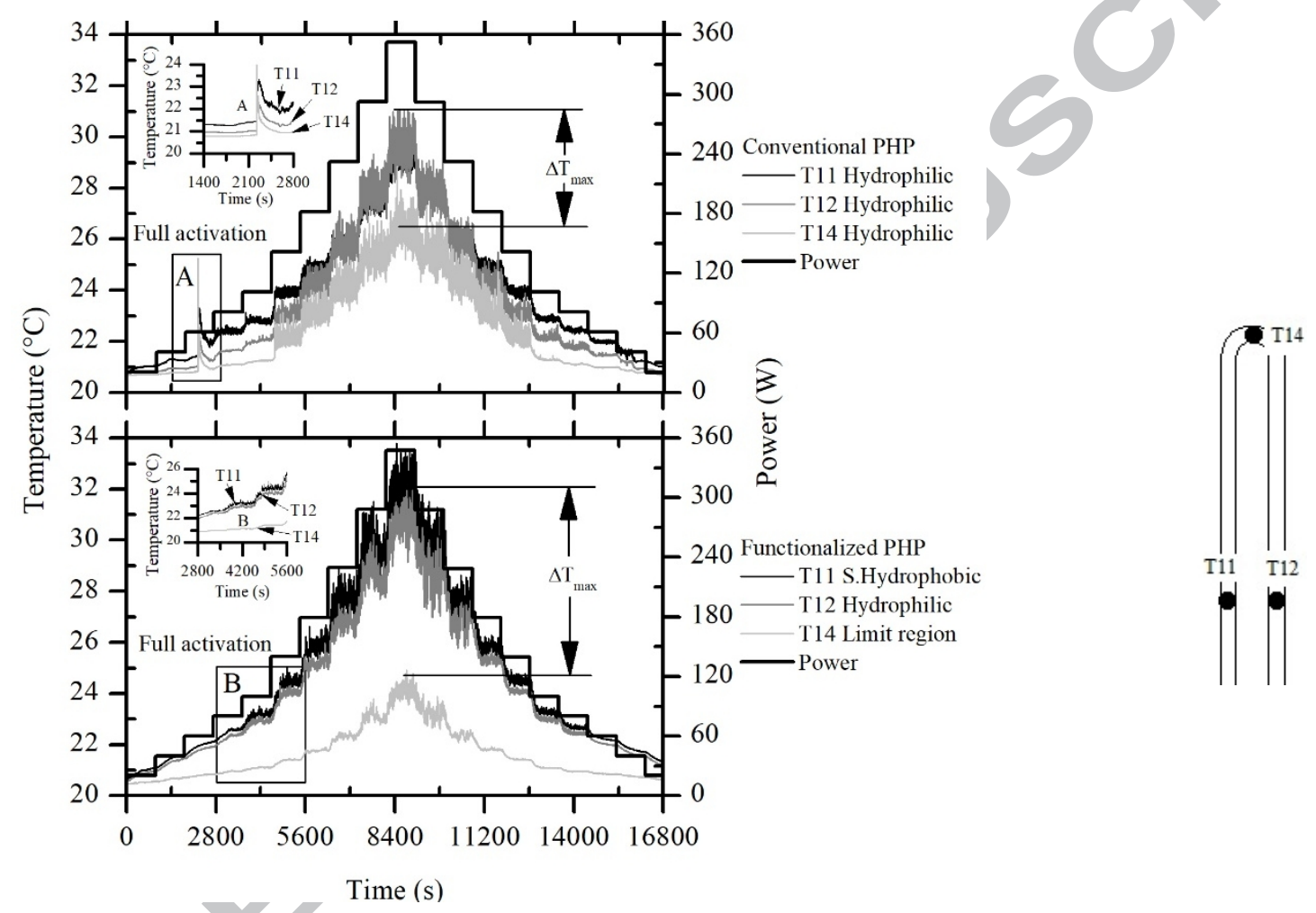

Fig. 4. Temperatures of a single turn for conventional and functionalized PHP. T12 measurement at functionalized PHP, located at superhydrophobic coated tube. For conventional PHP, T11 and T12 are overlapped for power inputs over $140 \mathrm{~W}$; in the case of functionalized PHP, T11>T12 for all the active power range.

Among the temperature curves for the conventional PHP shown in Fig. 4, T14 shows the smaller temperature levels, possibly because, of the three thermocouple positions, it is located farther from the evaporator. The comparison between $\mathrm{T} 11$ and $\mathrm{T} 12$ shows that $\mathrm{T} 11$ temperatures are higher for power levels lower than $140 \mathrm{~W}$. After this level, T11 and T12 oscillate around similar temperature levels, showing a full activation of the device as PHP; the fact that the $\Delta T$ for these three temperature measurements (T11, T12 and T14) is lower in the conventional PHP can be linked to a better flow motion in the channel. The same behavior is observed for increasing and decreasing power levels. Fig. 4 also depicts that functionalized PHP operation mode was different from the conventional one. T11, which is located on the functionalized superhydrophobic coating tube region, always presents a higher temperature than T12, located on hydrophilic channel. In addition, the temperature oscillations are larger for the superhydrophobic inserts rather than those for the bare (hydrophilic) tube regions. These temperature measurements suggest that the fluid flow oscillates preferentially inside the hydrophilic channel, which means that the chaotic two-phase flow motion is hindered at the functionalized PHP. Furthermore, Fig. 4 also shows that conventional PHP needs less time to achieve start-up conditions, observed when the temperatures start to oscillate. For all power inputs, the evaporator temperatures were higher for functionalized PHP. In addition, for the functionalized PHP, following the power decreasing trend, one observes 
that the temperature oscillations reduces sharply at low power levels, meaning that most the liquid phase oscillates at low amplitude, as the temperature oscillations detected in the condenser are very small.

Figure 5 presents the difference between evaporator and condenser mean temperatures, for both functionalized and non-functionalized (conventional) PHPs, as a function of time. This figure also presents the fluid pressure at the condenser zone. One can note that the PHP oscillations and temperature differences are strongly affected by wettability. Also, in the conventional PHP, oscillation starts after a high pressure peak that characterizes the PHP activation, which happens at a power of $60 \mathrm{~W}$. However, for the functionalized PHP, the initial pressure oscillations happened at almost a double level of heating power (100W). In addition, the pressure trends are different between the two cases. In the conventional PHP, there is a vigorous peak of pressure during the start-up and, at the same time, all the temperatures at the evaporator decrease abruptly, due to the full activation of the two-phase oscillating flow between the heated and the cooled region. In the functionalized PHP, the pressure peak does not exist and only some oscillations of the average values of temperature can be recognized, without a drop in the heated section. The low wettability of the superhydrophobic sections of the PHP hinders a proper full start-up. This could be attributed to the intensification of pressure drops along the superhydrophobic sections and, according to [21], the driving (activation) pressure increases as the advancing contact angle increases, and so the contact angle becomes the primary contribution parameter to the flow resistance in a capillary tube. According to Srivinassan et al. [22], the flow structure is strongly affected by the transversal velocity components, especially near the meniscus region, where vortex e recirculation zones are created, influencing the pressure drops. This shows the relevance of the dynamic contact angle behavior and of the flow field in the oscillation of liquid Taylor plugs. The decreasing of the wettability in a capillary tube results in an increment of the pressure drop, as the liquid film formation is delayed within the superhydrophobic tube. Therefore, the heating power needed to activate liquid-vapor phase change is higher for superhydrophobic internal loop surfaces than for the hydrophilic loop (bare metal). The analysis of $\Delta \mathrm{T}$ as a function of time, in Fig. 5, allows for the identification of the PHP start-up and of the oscillation onset. In summary, functionalized PHP starts up at higher power levels and at higher mean temperature levels.

It is possible to identify two different start-up modes for the two PHPs, as also observed in the literature by Liu et al, 2013 [23]. For both PHPs, the heat transfer mechanism before the start-up is conduction. For the functionalized PHP and for power levels below $100 \mathrm{~W}$, considering that the liquid is saturated, the condenser pressure, around $2.3 \mathrm{kPa}$, is controlled by the cooling bath water temperature, kept at $20^{\circ} \mathrm{C}$. Actually, up to this power level, thermal oscillations at condenser zone are not observed, only independent temperature oscillations at evaporator zone. However, the conventional PHP studied achieves start-up conditions at 40W.

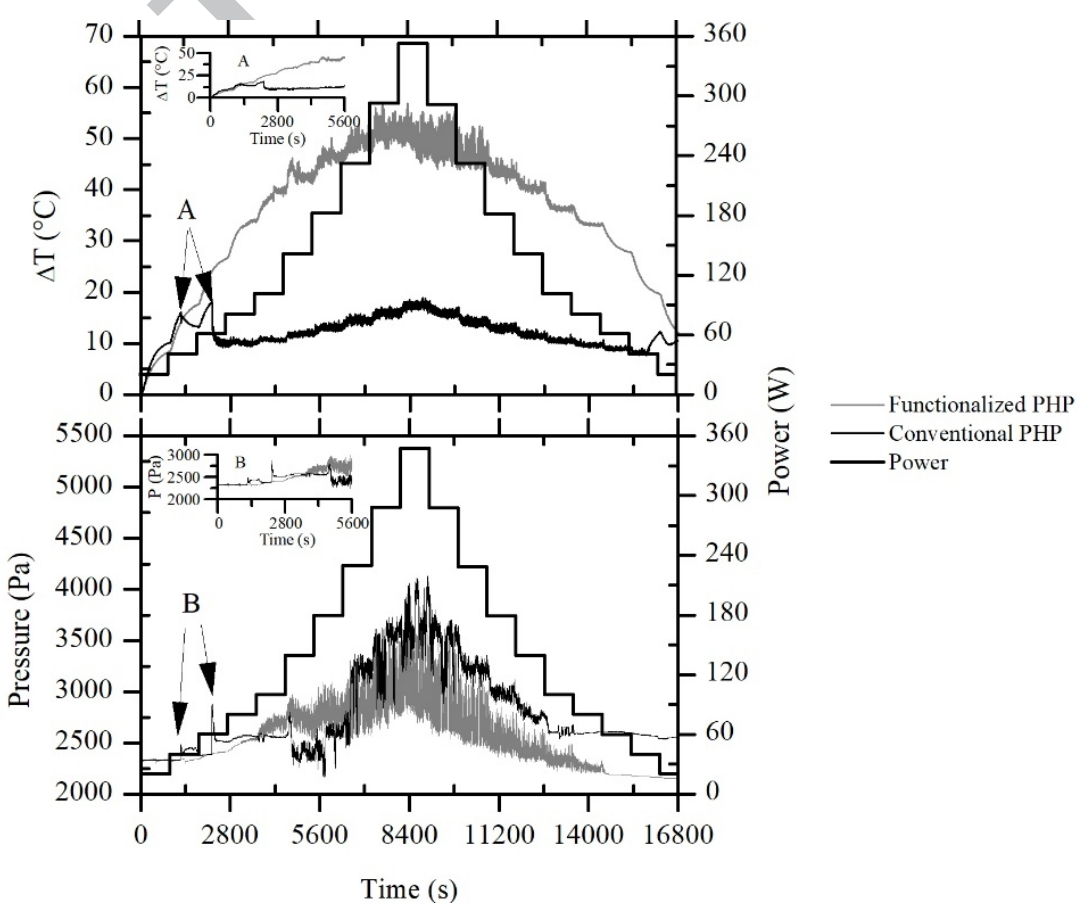


Fig. 5. Mean $\Delta \mathrm{T}$ and pressure at condenser zone. Start-up for conventional PHP at $40 \mathrm{~W}$ and full activation at $60 \mathrm{~W}$. For functionalized PHP, start-up conditions are achieved at $80 \mathrm{~W}$ and full activation at $100 \mathrm{~W}$. Pressure at condenser zone for conventional and functionalized PHPs achieves maximum values of $4.1 \mathrm{kPa}$ and $3.5 \mathrm{kPa}$ respectively, controlled by $\mathrm{T}_{\mathrm{c}}$.

Figure 6 presents the behavior of T15 and T16 temperatures (located at the end of the condenser zone) for both PHPs. The observation of these temperatures gives an indication of when the oscillating fluid reaches the condenser upper position, where the pressure transducer is installed. The temperatures readings for thermocouples T15 and T16 for the conventional PHP, show that the temperatures are strongly affected by the fluid oscillations, especially when the device achieves start-up conditions, where the oscillations amplitude increase. On the other side, T15 and T16 temperatures for functionalized PHP show a completely different behavior, as the condenser upper region is only slightly affected, for power inputs lower than $140 \mathrm{~W}$. One can see clearly a temperature increase with the power increase, but the oscillations were almost imperceptible, especially for power levels below 140W. For higher power inputs, T15 and T16 temperatures start to oscillate, but with low amplitudes. This small temperature oscillation shows that the flow possibly tends to be unidirectional. Further visualization experimental work is necessary to determine the type and direction of flow. Furthermore, T15 (located at the bare cooper tube) shows lower temperature fluctuations than those of T16, indicating strongest oscillations at channel 1 as compared to channel 10. Conventional and functionalized PHPs show different oscillation patterns, as the low wettability of the functionalized tube hinders the flow motion. Actually, T15 and T16 for the functionalized PHP temperatures are close to $21^{\circ} \mathrm{C}$, which is approximately the thermal bath temperature.

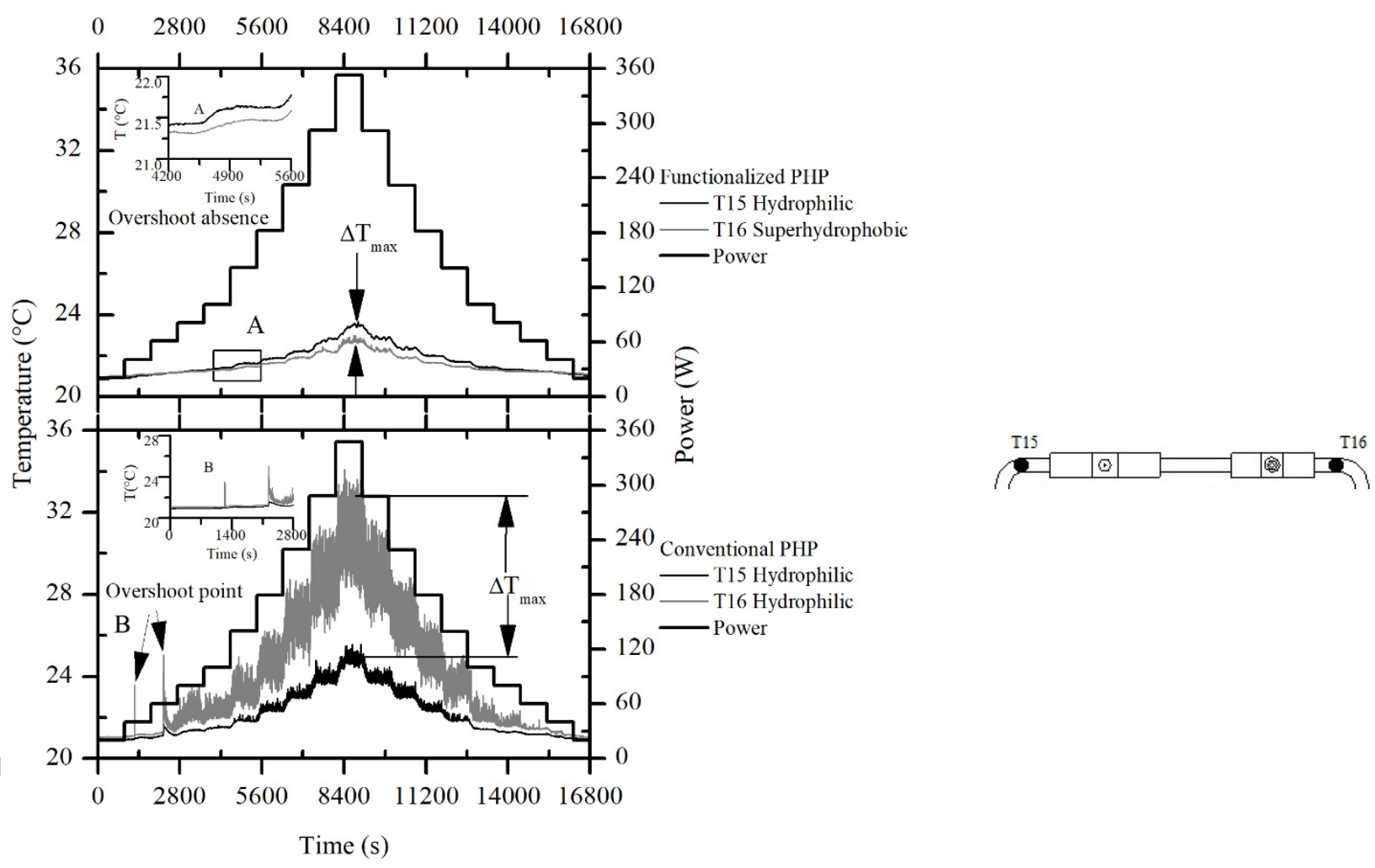

Fig. 6. Temperature performance of T15-T16. Located at the condenser end. T16 position near to pressure transducer

The pressure drops increases with decreasing the wettability of capillary tubes, as it is difficult to form liquid film along the tube [24]. Besides, the liquid film acts as a lubricant, helping the flow to move along the serpentine [17] and a thin liquid film, that depends of wettability, it is formed upstream side, when a liquid slug is dislocated [25]. This liquid film affects the evaporation mass flux. Hampering the liquid film formation causes start-up delays and holds back the overall flow motion, decreasing the PHP thermal performance, when compared with traditional PHP operating under the same conditions. 
Equivalent thermal resistance $\left(\mathrm{R}_{\mathrm{t}}\right)$ concept is used to express the performance of the PHPs. $\mathrm{R}_{t}$ is defined as the ratio between the mean temperature difference $(\Delta \mathrm{T})$ between the evaporator $\left(\bar{T}_{e}=\left(\sum_{i=1}^{10} T_{i}\right) / 10\right)$ and condenser $\left(\bar{T}_{c}=\left(\sum_{i=11}^{16} T_{i}\right) / 6\right.$, where $\mathrm{i}=\mathrm{i}^{\text {th }}$ thermocouple and the heating power transported by the $\mathrm{PHP}(\mathrm{Q})$ :

$$
\mathrm{R}_{\mathrm{t}}=\frac{\Delta \mathrm{T}}{\mathrm{Q}}
$$

In Fig. 7, the overall thermal resistance is plotted against the power input for the functionalized PHP and compared with conventional PHP, for both testing conditions: increasing and decreasing the power input levels. The maximum uncertainty for the equivalent resistance was calculated to be less than $2 \%$. For both cases, the thermal resistance decreases with the increase of the transported heat power, up to the maximum experimentally applied power input (350W). Moreover, for all power levels, thermal resistance is higher for functionalized PHP. Only when the power input levels are small and both PHPs are not full activated, the thermal resistances presents similar values. This is expected as, in this level, conduction heat transfer takes the most important role. Moreover, an odd behavior is observed for the functionalized PHP at lower decreasing power input levels, when the resistance tends to a plateau. Actually, after the PHP is activated, even with the power supply decrease at levels lower than those required for its activation, the device does not remains active. Therefore, for the functionalized PHP, the thermal power necessary to reach start-up is less than the minimum power required to sustain the fluid motion.

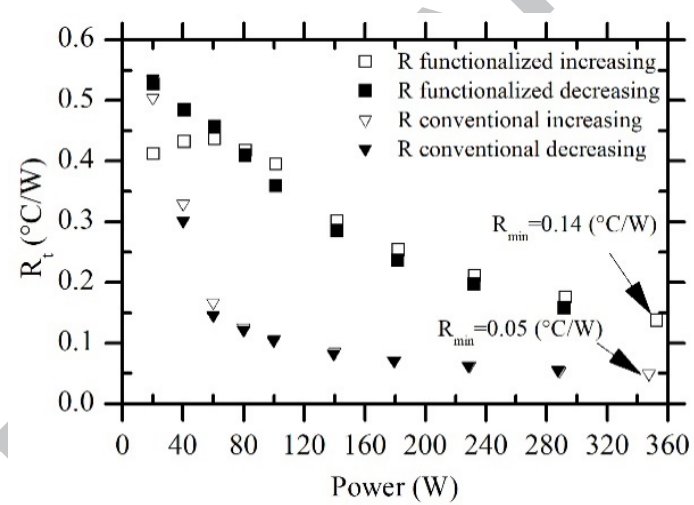

Fig. 7. Thermal resistance. Increasing and decreasing model. Hysteresis is observed mainly at low power inputs for functionalized PHP. At full activation, hysteresis of the thermal resistance is negligible.

Figure 7 also shows that, after the conventional PHP two-phase flow motion is fully activated, the thermal resistance tends to stabilize in a defined plateau. On the other side, the thermal resistance of the functionalized PHP continues to decrease with increasing supplied power. This can happen because, as the heat transfer due to the oscillation motion is not very effective in this case, the working fluid convection heat transfer, which tends to be the dominant heat transfer mechanism, increases with the temperature increase.

A summary of the operating conditions for both PHPs is presented in Table 2. The start-up (S) is considered achieved when oscillation is observed in any U-bend, while "full activation condition F", when oscillations are observed in the whole device.

Table 2. Start-up comparison at different power levels.

\begin{tabular}{ccc}
\hline Power $[\mathrm{W}]$ & Conventional & Functionalized \\
\hline 20 & $\mathrm{~N}$ & $\mathrm{~N}$ \\
40 & $\mathrm{~S}$ & $\mathrm{~N}$ \\
60 & $\mathrm{~F}$ & $\mathrm{~N}$ \\
80 & $\mathrm{~F}$ & $\mathrm{~S}$ \\
100 & $\mathrm{~F}$ & $\mathrm{~F}$ \\
$140-350-140$ & $\mathrm{~F}$ & $\mathrm{~F}$ \\
100 & $\mathrm{~F}$ & $\mathrm{~F}$ \\
80 & $\mathrm{~F}$ & $\mathrm{~F}$ \\
60 & $\mathrm{~F}$ & $\mathrm{~N}$ \\
40 & $\mathrm{~N}$ & $\mathrm{~N}$
\end{tabular}




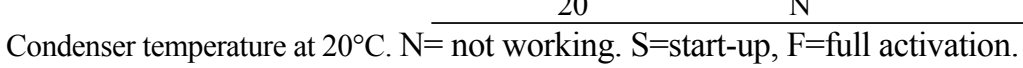

Figure 8 shows the temperature behavior of both PHP when the devices, departing from the off condition (no power input) receive $80 \mathrm{~W}$ of power. It is observed that the start-up behavior is quite different. The maximum temperature measurement for conventional PHP was around $37^{\circ} \mathrm{C}$ before start-up, while for the functionalized device it was around $78^{\circ} \mathrm{C}$. The highest and the lowest evaporator temperature levels, for conventional PHP are observed for thermocouples T7 and T6, respectively. These thermocouples are located close to central regions of the PHP. Also in Figure 8 one notes that, for both cases, the temperature readings from thermocouples located at the condenser zone presented very small oscillations, which are larger during the start-up, decreasing considerably after 1,500 seconds. In this figure (as in Figures 4, 5 and 6), considering the functionalized PHP, results show that the start-up happens without temperature overshoot and that the oscillations are observed only for the evaporator temperature readings and the evaporator temperatures decrease in the order: T4, T10, T7, T8, T6, T9, T5, T2, T3 and T1, showing a local unidirectional trend, as: T5<T6, T9<T10, T3<T4, T1<T2; only $\mathrm{T} 8<\mathrm{T} 7$, not following this trend. Besides, $\mathrm{T} 11$ and $\mathrm{T} 12$, which are located in the middle region of the device, have similar levels and show oscillations in the temperature reading, while T15 and T16 do not oscillate. Although local flow unidirectional could be observed, the global one possibly does not exist.

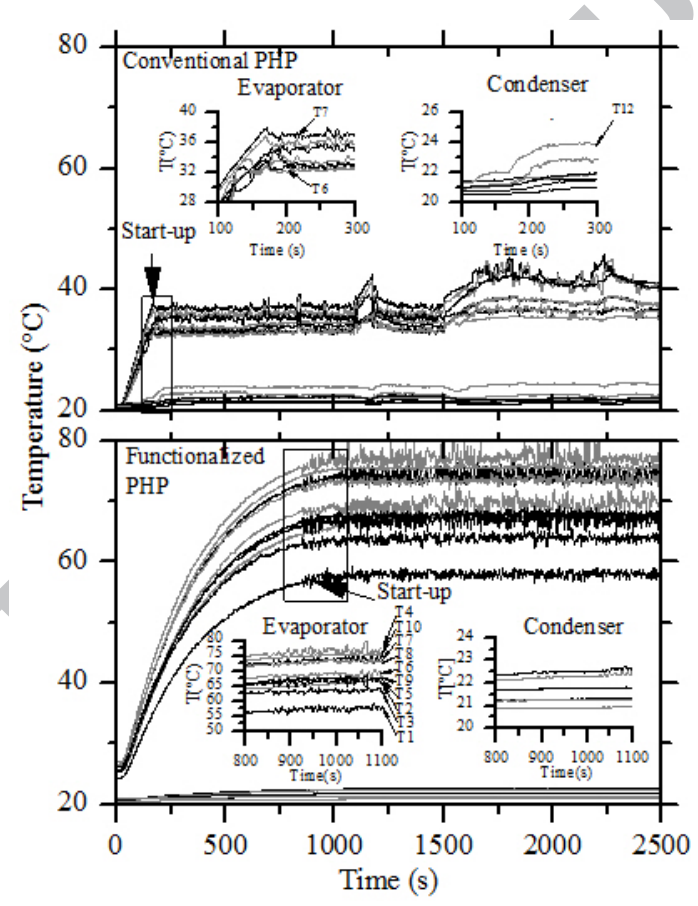

Fig. 8. Start-up for conventional PHP and functionalized PHP at $80 \mathrm{~W}$, vertical position, bottom heat mode. Conventional one start-up occurred at $\sim 200$ s and overshoot start-up mode. Start-up at functionalized one occurred at $\sim 700$ s smooth startup mode.

\section{CONCLUSIONS}

The heat transfer performance of the alternating functionalized PHP (half of the tubes are superhydrophobic), partially filled with water, and is investigated experimentally for the condenser at constant temperature of $20^{\circ} \mathrm{C}$ and vertical position, bottom heat mode. Results are compared to a completely hydrophilic PHP, under the same working conditions. The data obtained showed that the thermal performance of functionalized PHP is lower, presenting higher thermal resistances. This behavior is different from the conventional PHP thermal resistances, especially for low and high heat power inputs.

Due to this low heat transfer characteristic, a relevant wall superheating before start-up is observed, as the major heat transport mechanism is the conduction through the solid material. Besides, functionalized PHP startup does not show an abruptly pressure increase, with consequent temperature decrease, as observed for 
conventional PHP. Therefore, wall temperatures at evaporator zone are always higher for functionalized PHP when compared to the conventional one.

The results also show that the minimum power level necessary to achieve start-up condition in functionalized PHP is higher when compared to the power level necessary for conventional PHP. For higher supplied power, temperature oscillations show higher amplitude at the evaporator of functionalized PHP, while in conventional PHP, the temperatures show stable and low amplitude oscillations. In addition, for a fixed and high power input, the functionalized PHP start-up takes more time than that of conventional PHPs. However, after the functionalized PHP starts to oscillate, the device keeps working in full activation mode, even with heat inputs lower than the power level necessary to achieve the start-up.

Thermal behavior hysteresis is observed at functionalized PHP as increasing or decreasing power causes different effects in the temperature levels of the PHP. This effect can be attributed to the reduction of the viscous and inertial forces of the liquid slugs, resulting from the operation conditions of conventional PHP. Further studies are recommended to analyze the effect of superhydrophobic layer in operational mechanisms, including the hysteresis.

In summary, alternating superhydrophobic-hydrophilic wettability unbalancing is not suitable to improve the thermal performance device; experimental results point out that the inner wettability is a very important parameter that needs to be taken into account during the PHP design. It is expected that, going on the opposite direction of the present research, enhancing the wettability will enhance the liquid film formation, enhancing, therefore, the working fluid flow motion within the PHP, decreasing the overall performance of the device. Furthermore, the PHP start-up would be reached at lower heating power levels and this study is left as suggestion for future works.

\section{ACKNOWLEDGEMENT}

Authors acknowledge Brazilian Space Agency for financial support. The authors acknowledge the help of all the members of the Heat Pipe Laboratory at the Federal University of Santa Catarina and of the Pulsating Heat Pipe International Scientific team.

This study was financed in part by the Coordenação de Aperfeiçoamento de Pessoal de Nível Superior - Brazil (CAPES) - Finance Code 001.

\section{REFERENCES}

[1] Sarno, C. and Tantolin, C., Integration, Cooling and Packaging Issues for Aerospace Equipments, Proc. Conf. Design, Automation and Test Europe, (2010)1225-1230. https://DOI: 10.1109/DATE.2010.5456994

[2] Faghri, A., Heat Pipe Science and Technology, First Ed. Taylor \& Francis, 1995.

[3] Akachi, H., Structure of a Heat Pipe, Patent US4921041A, 1990

[4] Maydanik, Y., Dmitrin, V. and Pastukhov, V., Compact Cooler for Electronics on the Basis of a Pulsating Heat Pipe, Applied Thermal Engineering, 29(17-18) 3511-3517. https://doi.org/10.1016/j.applthermaleng.2009.06.005

[5] de Souza, F., Destri, J. and Colle, S., An Experimental Investigation of a $\mathrm{CO}_{2}$ Pulsating Heat Pipe, Proc. of 14th International Heat Pipe Conference, Florianopolis, Brazil (2007).

[6] Zhang., Y. and Faghri, A., Advances and Unsolved Issues in Pulsating Heat Pipes, Heat Transfer Engineering, 29(1) (2008) 20-44. https://doi.org/10.1080/01457630701677114

[7] Pastukhov, V. and Maydanik, Y., Development of a Pulsating Heat Pipe with a Directional Circulation of a Working Fluid, Applied Thermal Engineering, $109 \quad$ (2016) $155-161$. https://doi.org/10.1016/j.applthermaleng.2016.08.076

[8] Chien, K., Lin, Y., Chen, Y., Yang, K. and Wang, C., A novel Design of Pulsating Heat Pipe with Fewer Turns Applicable to All Orientations, International Journal of Heat and Mass Transfer. 55(21-22) (2012) 5722-5728. https://doi.org/10.1016/j.ijheatmasstransfer.2012.05.068

[9] Hao, T., Ma, X., Lan, Z., Li, N., Zhao, Y. and Ma, H., Effects of Hydrophilic Surface on Heat Transfer Performance and Oscillating Motion for an Oscillating Heat Pipe, International Journal of Heat and Mass Transfer, 72 (2014) 50-65. https://doi.org/10.1016/j.ijheatmasstransfer.2014.01.007

[10]Hao, T., Ma, X., Lan, Z., Li, N. and Zhao, Y., Effects of Superhydrophobic and Superhydrophilic Surfaces on Heat Transfer and Oscillating Motion of an Oscillating Heat Pipe, Journal of Heat Transfer, 136 (8) (2014) 082001082001-13. https://doi:10.1115/1.4027390

[11]Ji, Y., Chen, H. Kim, Y., Yu, Q., Ma, X., and Ma, H.B., Hydrophobic Surface Effect on Heat Transfer Performance in an Oscillating Heat Pipe, Journal of Heat Transfer, 134 (7) (2012) 074502-074502-4. https://doi:10.1115/1.4006111 
[12]Bertossi, R., Ayel, V., Mehta, B., Romestant, C., Bertin, Y., and S. Khandekar, Motion of Liquid Plugs Between Vapor Bubbles in Capillary Tubes: a Comparison Between Fluids, Heat Mass Transfer, 53 (11) (2017) 3315-3327. https://doi.org/10.1007/s00231-017-2052-1

[13]Vemuri, S. and Kim, K.J., An Experimental and Theoretical Study on the Concept of Dropwise Condensation, International Journal of Heat and Mass Transfer, 49 (2006)649-657. https://doi.org/10.1016/j.ijheatmasstransfer.2005.08.016

[14]Liu, T., Li, P.L., Liu, C.W. and Gau, C., Boiling Flow Characteristics in Microchannels with very Hydrophobic Surface to Super-hydrophilic Surface, International Journal of Heat and Mass Transfer, 54 (2011) 126-134. https://doi.org/10.1016/j.ijheatmasstransfer.2010.09.060

[15]Srinivasan, V., and Khandekar, S., Thermo-hydrodynamic Transport Phenomena in Partially Wetting Liquid Plugs Moving Inside Micro-channels, Sadhana, 42 (4) (2017)607-624. https://doi.org/10.1007/s12046-017-0618-8

[16]Yang, K., Cheng, Y., Liu, M., and Shyu, J., Micro Pulsating Heat Pipes with Alternate Microchannel Widths, Applied Thermal Engineering, 83 (2015)131-138. https://doi.org/10.1016/j.applthermaleng.2015.03.020

[17]Rapolu, P. and Son, S., Characterization of Wettability Effects on Pressure Drop of Two-phase Flow in Microchannel, Experimental in Fluids, 51(4) (2011) 1101-1108. https://doi.org/10.1007/s00348-011-1129-8

[18] Barajas, A., and Panton, R., The Effects of Contact Angle on Two-phase Flow in Capillary Tubes, International Journal of Multiphase Flow, 19(2) (1993) 337-346. https://doi.org/10.1016/0301-9322(93)90007-H

[19]Betancur, L., Mangini, D., Mameli, M., Filippeschi, S., Slongo, L., Paiva, K., Mantelli, M., Marengo, M., Effect of Condenser Temperature on the Start-up of a Pulsating Heat Pipe, Heat Pipe Science and Technology, An International Journal, 8(1) (2017) 13-25. https://doi.org/10.1615/HeatPipeScieTech.2017018910

[20]Lee, C. and Lee, S., Pressure Drop of Two-phase Plug Flow in Round Mini-channels: Influence of Surface Wettability, Experimental Thermal and Fluid Science, $32 \quad$ (8) (2008) 1716-1722. https://doi.org/10.1016/j.expthermflusci.2008.06.007

[21] Ma, Y.D., Motion Effect on the Dynamic Contact Angles in a Capillary Tube, Microfluid. Nanofluidics, 12(1-4) (2012)671-675. https://doi.org/10.1007/s10404-011-0894-2

[22]Srinivasan, V., Kumar, S., Asfer, M. and S. Khandekar, Oscillation of an Isolated Liquid Plug Inside a Dry Capillary, Heat Mass Transfer, 53(11) (2017) 3353-3362. DOI 10.1007/s00231-017-2064-X

[23]Liu, X., Chen, Y. and Shi, M., Dynamic Performance Analysis on Start-up of Closed-loop Pulsating Heat Pipes (CLPHPs), International Journal of Thermal Sciences, $65 \quad$ (2013) $224-233$. https://doi.org/10.1016/j.ijthermalsci.2012.10.012

[24]Rapolu, P., and Son, S. Y., Capillarity Effect on Two-phase Flow Resistance in Microchannels, ASME 2007 International Mechanical Engineering Congress and Exposition, (8) (2007) 1039-1045. https://doi.org/10.1115/IMECE2007-42719

[25]Srinivasan, V., Marty-Jourjon, V., Khandekar, S., Lefèvre, F., Bonjour, J. Evaporation of an Isolated Liquid Plug Moving Inside a Capillary Tube, International Journal of Heat and Mass Transfer, 89 (2015) 176-185. http://dx.doi.org/10.1016/j.ijheatmasstransfer.2015.03.013 


\section{Highlights}

- Surface wettability influences the vapor and liquid slug motion and so, the thermal performance of pulsating heat pipes.

- Pulsating heat pipes containing inner hybrid hydrophilic-hydrophobic Surface at evaporator zone and condenser zone respectively presents a better thermal performance when compared to homogeneous ones.

- Capillary unbalancing at pulsating heat pies improves the thermal performance and decreases the gravity dependence.

- Literature does not report the effect of alternating channels with hydrophilic and superhydrophobic coatings to create capillary unbalancing and analyze the effect in the thermal performance. 